\title{
Tree-ring density inferred late summer temperature variability over the past three centuries in the Gaoligong Mountains, southeastern Tibetan Plateau
}

\author{
Ming-Yong Li $^{\text {a,b }}$, Lily Wang ${ }^{\mathrm{a}, *}$, Ze-Xin Fan ${ }^{\mathrm{c}}$, Chen-Chen Shen ${ }^{\mathrm{a}, \mathrm{b}}$ \\ a Key Laboratory of Land Surface Pattern and Simulation, Institute of Geographic Sciences and Natural Resources Research, Chinese Academy of Sciences, Beijing 100101, China \\ b University of Chinese Academy of Sciences, Beijing 100049, China \\ c Key Laboratory of Tropical Forest Ecology, Xishuangbanna Tropical Botanical Garden, Chinese Academy of Sciences, Kunming 650223, China
}

\section{A R T I C L E I N F O}

\section{Article history:}

Received 29 July 2014

Received in revised form 23 December 2014

Accepted 7 January 2015

Available online 12 January 2015

\section{Keywords:}

Tree rings

Maximum latewood density

Larix speciosa

August-September temperature

Southeastern Tibetan Plateau

\begin{abstract}
A B S T R A C T
Long and high-resolution proxy records are still sparse in the southeastern Tibetan Plateau (TP), hampering our understanding of past climatic variability from a long-term perspective. In this study, we developed a regional maximum latewood density (MXD) chronology of Larix speciosa stretching up to 523 years based on 72 treering cores (44 trees) collected from three sites close to the tree line in the Gaoligong Mountains, southeastern TP. This chronology responded well to temperatures during August through September and was thus used to reconstruct late summer (August-September) temperature over the period A.D. 1690-2008. The reconstruction explains $40.9 \%$ of the total temperature variance during the calibration phase. Cold conditions prevailed during the periods $1695-1702,1806-1821$, the 1850 s, $1882-1889$, the 1900 s and the 1960 s. Warm phases occurred in 1734-1745, the 1770s, 1824-1840, the 1890s, 1927-1936, the 1940s-1950s and 2002-2008. Spatial correlation with the gridded temperature data set showed that our reconstruction captures large-scale regional temperature variations for the southeastern and southern TP. Comparison with other tree-ring inferred temperature time series in the surrounding areas, glacier fluctuations and historical documental records imply a high degree of confidence for our reconstruction.
\end{abstract}

(c) 2015 Elsevier B.V. All rights reserved.

\section{Introduction}

The Tibetan Plateau (TP), with an average altitude above $4000 \mathrm{~m}$ a.s.l. and a total area of more than 2 million $\mathrm{km}^{2}$, deeply affects large-scale atmospheric circulation pattern in its neighborhood, such as the eastern and southern Asian monsoons and even the global climate system (Manabe and Terpstra, 1974). Investigating climate variation over the TP thus provides an effective way to interpret monsoon dynamics and global climate change. However, instrumental climate records on the TP are sparse and of short length (most of the climate data are available only after the 1950s), limiting our understanding of long-term climate change in the region. Therefore, it is necessary to extend the available climate data over TP back in time by developing climate proxy records.

Tree-ring data have been increasingly used to reconstruct highresolution and long-term climate change of the TP in the last decades. However, the dendroclimatic studies on the TP are very uneven in spatial distribution. Many works focused on precipitation/drought

\footnotetext{
* Corresponding author at: Key Laboratory of Land Surface Pattern and Simulation, Institute of Geographic Sciences and Natural Resources Research, Chinese Academy of Sciences, 11A, Datun Road, Chaoyang District, Beijing 100101, China. Tel.: + 8610 64889321.

E-mail address: wangll@igsnrr.ac.cn (L. Wang).
}

reconstructions on the northeastern TP (e.g. Zhang and Wu, 1997; Zhang et al., 2003, 2013; Shao et al., 2005; Liu et al., 2006) and temperature reconstructions in the eastern and northeastern parts of the plateau (e.g. Liu et al., 2005, 2009; Gou et al., 2007, 2008; Xu et al., 2011). The southern and southeastern parts of the TP, however, have received much less attention, although they are widely covered by forests. To date, limited dendroclimatic researches have been conducted in these areas, most of which employed tree-ring width or isotope to reconstruct climate history (Fan et al., 2008, 2010; Liang et al., 2009; Zhu et al., 2011; Li et al., 2012; Sano et al., 2013; Yadav et al., 2014). Few studies used treering density as a climate proxy in these regions (Bräuning and Mantwill, 2004; Bräuning, 2006; Fan et al., 2009), even though tree-ring maximum latewood density (MXD) has been demonstrated to have a great potential for temperature reconstruction (Schweingruber, 1988; Briffa et al., 1992). Dendroclimatic researches involving more sites, species and tree-ring parameters are needed in the southern and southeastern TP.

Larix speciosa is a deciduous pioneer tree species mainly distributed in the Gaoligong, Nu, and Xuelong Mountains, southeastern TP (Wang and Zhang, 1992). Fan et al. (2010) found the tree-ring width of this species from the Gaoligong Mountains responded well to temperatures during the growing season and thus reconstructed mean May-August temperature history. Here in this study, we developed a regional MXD chronology of $L$. speciosa and used this chronology to infer late summer 
(August-September) temperature variations during the period A.D. 1690-2008 for our study area.

\section{Materials and methods}

\subsection{Study area and climate}

The study area was in the Gaoligong Mountains which is the border area of northwest of Yunnan province, China and northeast of Burma (Fig. 1). The Mountains are incised by deep gorges of Nujiang River and Irrawaddy River, forming extremely steep physiognomy in the region. The Gaoligong Mountains are considered as one of the biodiversity hotspots in the world (Myers et al., 2000), where the flora is highly rich, including more than 4294 seed plant species (Wang et al., 2007). Along the elevation gradient, the vegetation from low to high altitudes is respectively tropical monsoon forest $(<1000 \mathrm{~m}$ a.s.l.), subtropical evergreen broad-leaf forest (1000-2600 m a.s.l.), temperate deciduous broad-leaf forest (1000-3000 $\mathrm{m}$ a.s.l.), sub-alpine coniferous forest (2700-3500 $\mathrm{m}$ a.s.l.), alpine meadow and tundra (>3400 $\mathrm{m}$ a.s.l.). The forest limit is located about $3500 \mathrm{~m}$ a.s.l. (Xue, 1995; Li et al., 2000).

The climate in our study area is mainly influenced by southwest Asian monsoon from the Indian Ocean, characterized by abundant precipitation during the summer half year and much less in the winter half year. Spatially, the climatic conditions (e.g. precipitation and temperature) vary according to terrain. Records from the meteorological station in Deqin $\left(28^{\circ} 29^{\prime} \mathrm{N}, 98^{\circ} 55^{\prime} \mathrm{E}, 3319 \mathrm{~m}\right.$ a.s.l.) close to our sampling site show that the mean annual temperature and precipitation during the period 1954-2008 are respectively $5.4^{\circ} \mathrm{C}$ and $648 \mathrm{~mm}$ (Fig. 2).

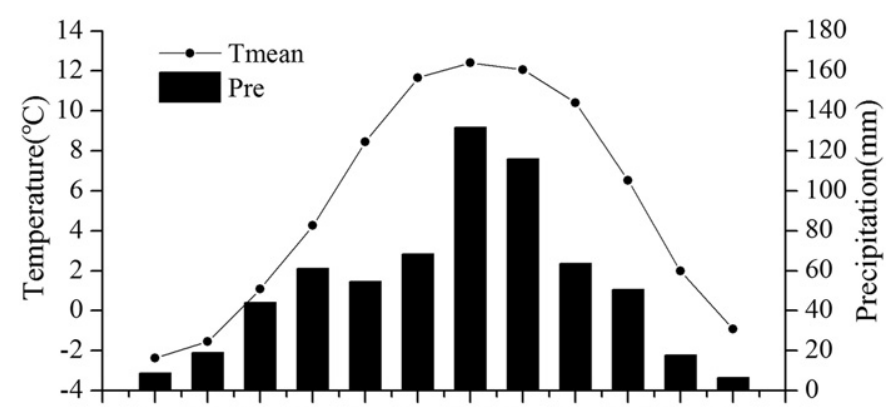

Jan Feb Mar Apr May Jun Jul Aug Sep Oct Nov Dec Months

Fig. 2. Monthly mean temperature (Tmean) and total precipitation (Pre) for the meteorological station in Denqin in the southeastern Tibetan Plateau during the period 1954-2008.

\subsection{Sample collection and chronology development}

Three sites (SKL, 42KM and DLJ) near the tree line in the Gaoligong Mountains, southeastern TP with little evidence of fire, insect attack or human disturbance were chosen for sampling (Fig. 1). These sites locate at 3200-3276 m a.s.l. In total, 72 cores from 44 trees were extracted using an increment borer at breast height, with 16, 9 and 19 trees being obtained from SKL, 42KM and DLJ sampling sites, respectively (Table 1).

In order to obtain the MXD data of $L$. speciosa, tree-ring samples were processed following the standard densitometric analysis procedure developed by the Swiss Federal Institute of Forest, Snow and Landscape

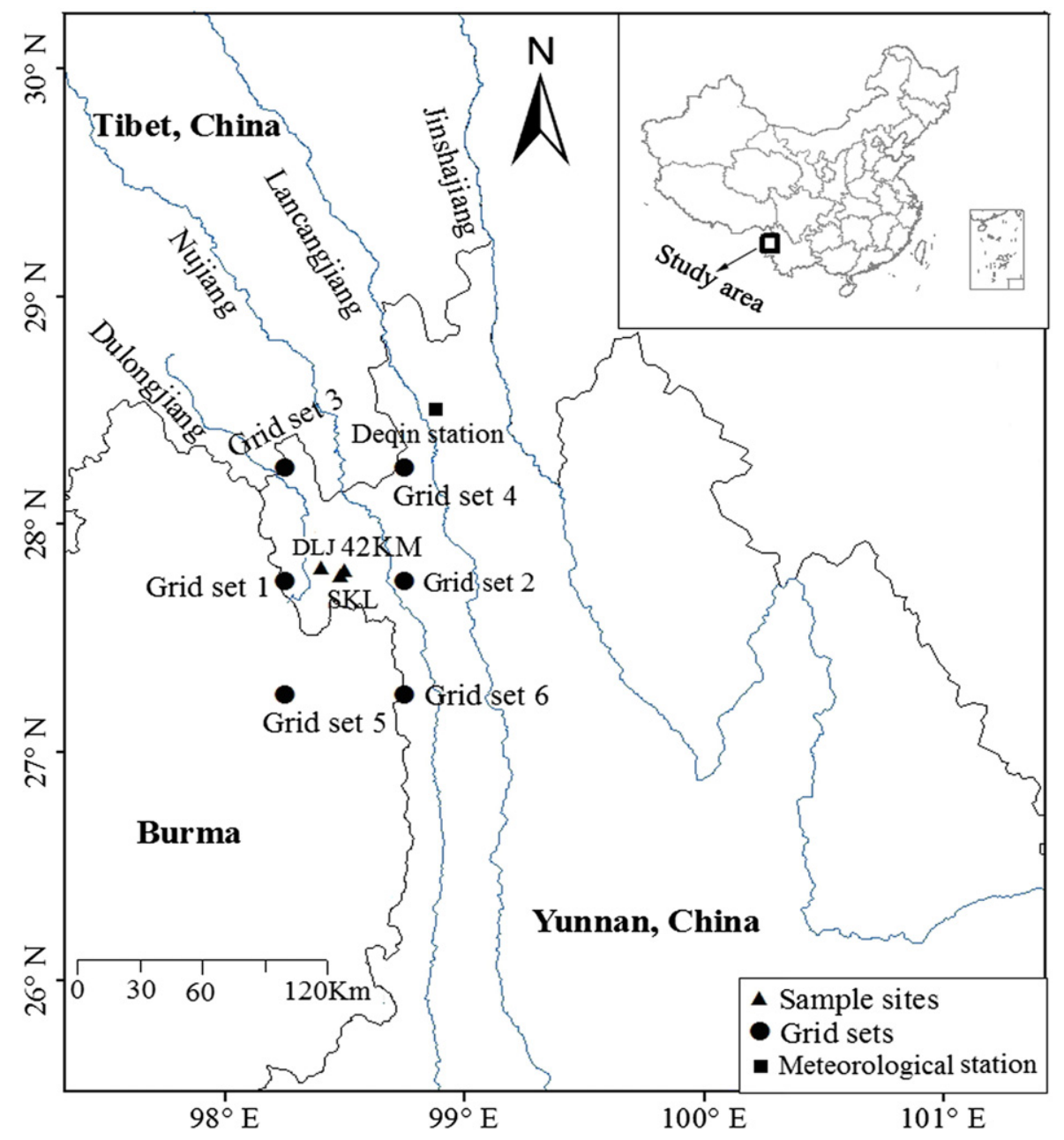

Fig. 1. Locations of the sampling sites, grid sites and meteorological station. 
Table 1

Information about the sampling sites and grid sets in the southeastern Tibetan Plateau.

\begin{tabular}{lllccc}
\hline Sites & Latitude & Longitude & Elevation & Time span & Years \\
\hline SKL & $27.78^{\circ} \mathrm{N}$ & $98.48^{\circ} \mathrm{E}$ & $3276 \mathrm{~m}$ & $1706-2008$ & 303 \\
42KM & $27.80^{\circ} \mathrm{N}$ & $98.50^{\circ} \mathrm{E}$ & $3217 \mathrm{~m}$ & $1798-2008$ & 211 \\
DLJ & $27.81^{\circ} \mathrm{N}$ & $98.41^{\circ} \mathrm{E}$ & $3200 \mathrm{~m}$ & $1486-2005$ & 520 \\
Grid set 1 & $27.75^{\circ} \mathrm{N}$ & $98.25^{\circ} \mathrm{E}$ & - & $1950-2008$ & 59 \\
Grid set 2 & $27.75^{\circ} \mathrm{N}$ & $98.75^{\circ} \mathrm{E}$ & - & $1950-2008$ & 59 \\
Grid set 3 & $28.25^{\circ} \mathrm{N}$ & $98.25^{\circ} \mathrm{E}$ & - & $1950-2008$ & 59 \\
Grid set 4 & $28.25^{\circ} \mathrm{N}$ & $98.75^{\circ} \mathrm{E}$ & - & $1950-2008$ & 59 \\
Grid set 5 & $27.25^{\circ} \mathrm{N}$ & $98.25^{\circ} \mathrm{E}$ & - & $1950-2008$ & 59 \\
Grid set 6 & $27.25^{\circ} \mathrm{N}$ & $98.75^{\circ} \mathrm{E}$ & - & $1950-2008$ & 59 \\
\hline
\end{tabular}

Research (Lenz et al., 1976; Schweingruber, 1988; Schweingruber et al., 1991). Tree cores were cut into $1.0-\mathrm{mm}$-thin sections using a twinblade DENDROCUT, with the angles vertical to the wood fiber, which were accomplished by a DENDROSCOPE (Wang et al., 2010). The resin and sugar in the thin wood sections were removed by soaking them in $80^{\circ} \mathrm{C}$ water for $72 \mathrm{~h}$. After being air-dried, the sections were put into a constant-temperature-and-humidity room for more than $2 \mathrm{~h}$ to ensure all of them have the same water content. Then, X-ray photography was taken using these sections in the same room. This process yielded greyscale variations in the X-ray film, from which the MXD measurements can be acquired by the DENDRO2003 instrument. The obtained MXD measurements were cross-dated using the COFECHA program (Holmes, 1983) and were verified with wood sections when inconsistencies occurred.

The dated MXD measurements were detrended by a cubic spline with a $50 \%$ frequency-response cutoff equal to $67 \%$ of the series length to remove the biological growth trend using ARSTAN program and preserve variations related to climate (Cook, 1985). This detrending method emphasized the inter-annual to multi-decadal scale variability (Cook and Kairiukstis, 1990). All detrended series were averaged to form the MXD standard chronology for each site (Fig. 3) by calculating the biweight robust means which can decrease the effect of outliers (Cook and Kairiukstis, 1990). As the site chronologies were highly correlated with each other during the period 1798-2005 (R: 0.589$0.651, \mathrm{P}<0.01$ ), we decided to combine all detrended MXD series from these sampling sites to develop a longer and better replicated regional MXD standard chronology (Fig. 3). The statistical characteristics of the site and regional chronologies are shown in Table 2. According to the Expressed Population Signal (EPS) threshold of 0.85 (Wigley et al., 1984; Cook and Kairiukstis, 1990), the regional chronology met the acceptable signal strength for climate reconstruction after A.D. 1690 (>16 cores).

\subsection{Climate-growth response and reconstruction}

In order to evaluate the response of tree growth to climate, we conducted bootstrapped correlation analysis between the regional MXD chronology and climate data for their common period using the DendroClim 2002 program (Biondi and Waikul, 2004). The gridded temperature and precipitation data (obtained from the Climate Research Unit (CRU TS 3.10) (Mitchell and Jones, 2005; Harris et al., 2013)), averaged from six grid sets near the sampling sites (Fig. 1) were used in our study for emphasizing the spatial representation. The climate variables include monthly mean temperature (Tmean) and total precipitation from previous October through current September.

A linear regression model was established for mean AugustSeptember temperature reconstruction by using the regional MXD chronology as the predictor. Since the available temperature data set is too short to be divided into two subsets for robust calibration and verification, we employed the leave-one-out cross-validation (Michaelsen, 1987) to verify our reconstruction. Evaluative statistics include Person's correlation coefficient $(r)$, sign test (ST) product mean test (Pmt) and reduction of error (RE) (Fritts, 1976). The cyclic patterns of the reconstructed temperature variability were investigated using the method of multiple-taper method (MTM) spectral analysis (Mann and Lees, 1996). To investigate the spatial representativity of our reconstruction, we performed a spatial correlation analysis between the reconstructed series and the gridded temperature data set of Climate Research Unit (CRU TS 3.10) using the KNMI (http://climexp.knmi.nl).
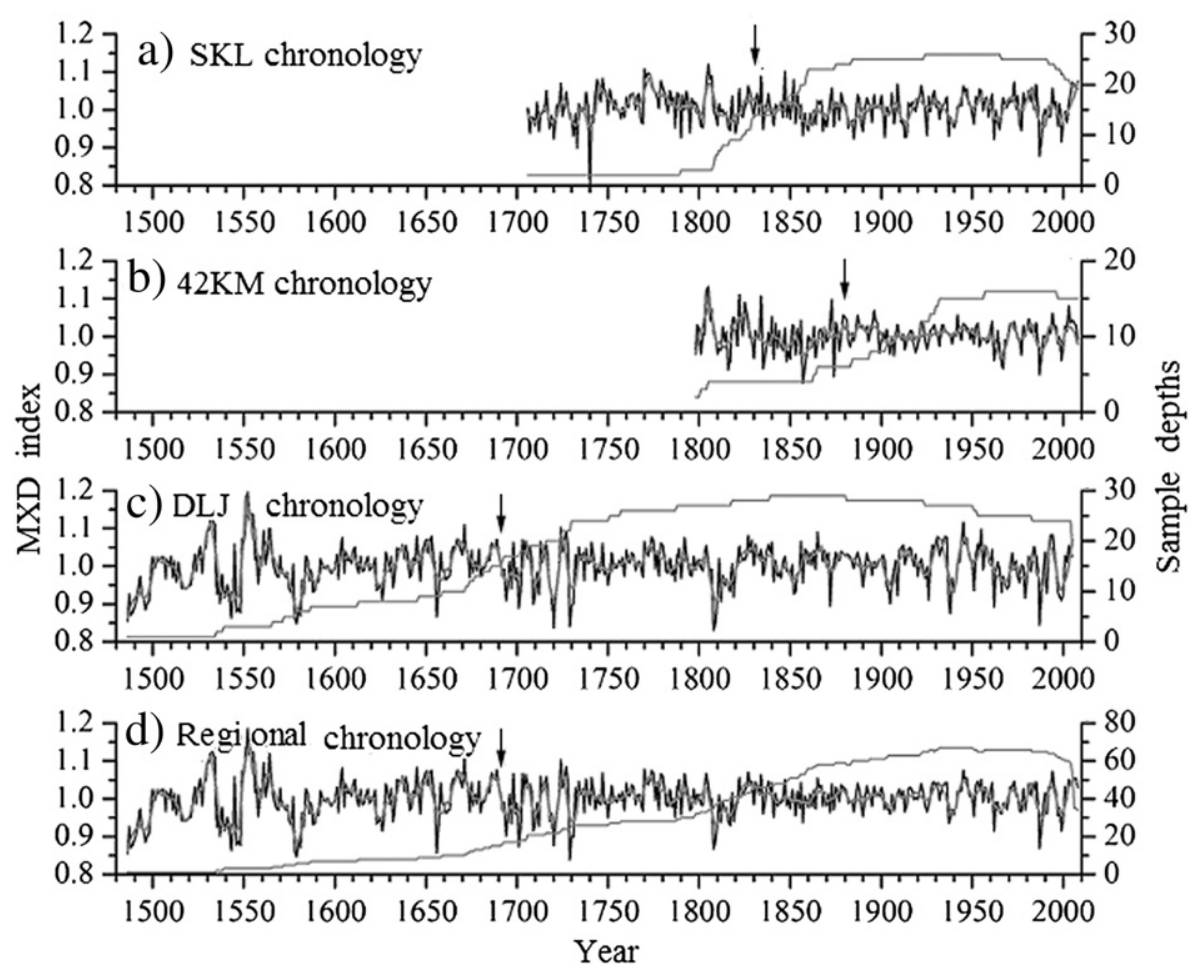

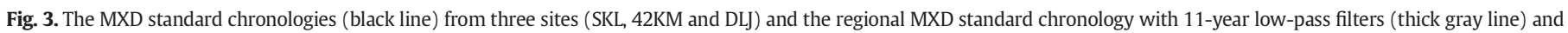
sample depths (gray line). The year with the Expressed Population Signal (EPS) $>0.85$ is marked using an arrow. 
Table 2

Statistics of the site and regional MXD standard chronologies.

\begin{tabular}{|c|c|c|c|c|c|c|c|c|}
\hline Chronologies & Time span & MLS & $\mathrm{R}$ & AC1 & MS & SD & Cores/trees & EPS $>0.85$ \\
\hline SKL & 1706-2008 & 182 & 0.425 & 0.437 & 0.045 & 0.052 & $26 / 16$ & $1830 / 14$ \\
\hline $42 \mathrm{KM}$ & 1798-2008 & 131 & 0.521 & 0.424 & 0.057 & 0.062 & $16 / 9$ & $1880 / 7$ \\
\hline DLJ & 1486-2005 & 310 & 0.383 & 0.450 & 0.041 & 0.048 & $30 / 19$ & $1690 / 16$ \\
\hline Regional & 1486-2008 & 224 & 0.369 & 0.418 & 0.038 & 0.045 & $72 / 44$ & $1690 / 16$ \\
\hline
\end{tabular}

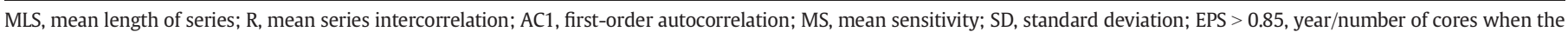
Expressed Population Signal exceeds the 0.85 threshold.

\section{Results}

\subsection{Climate responses of the MXD of Larix speciosa}

The regional MXD chronology showed significant positive correlations $(\mathrm{P}<0.01)$ with monthly mean temperatures from August to September over the period 1950-2008 (Fig. 4). Higher correlations were exhibited between the MXD indices and seasonal temperature. The correlation coefficient for the average August-September temperature (late summer) reached $0.640(P<0.01)$, which was much greater than those for individually monthly temperatures. Therefore, we employed the MXD chronology to reconstruct the mean August-September temperature history in our study area.

\subsection{Calibration and reconstruction of mean August-September tempe rature}

The statistics of the calibration and verification test are shown in Table 3. The regression model $(Y=7.355 X+6.058)$ accounts for $40.9 \%\left(R_{\text {adj }}^{2}=39.9 \%\right)$ of the actual variance of the mean AugustSeptember temperature during the calibration period 1950-2008 (Fig. 5). Also, this model passes all conventional calibration statistics $(R=0.640, F=39.503, \mathrm{P}<0.01)$. The leave-one-out cross validation test produced a positive RE (0.364), revealing the predictive skill of the regression model (Fritts, 1976). Statistical significant sign test $(41+/ 18-, \mathrm{P}<0.01)$ and correlation $(r=0.605, \mathrm{P}<0.01)$ between the actual values and the leave-one-out estimates indicated validity of the reconstruction. We calibrated further the first differences of the MXD indices with those of actual temperature data, which explained $36.9 \%\left(R_{\text {adj }}^{2}=35.8 \%\right)$ of the actual August-September temperature variances over the calibration period (1951-2008) (Table 3). The leave-one-out cross validation test yielded significant $(P<0.01)$ verification statistics ( $r$ : 0.499; ST: $47+/ 11-$ ) and positive RE (0.254), indicating that the developed model using the first difference of MXD index as the independent variable was able to capture the temperature variability at high-frequency domain.

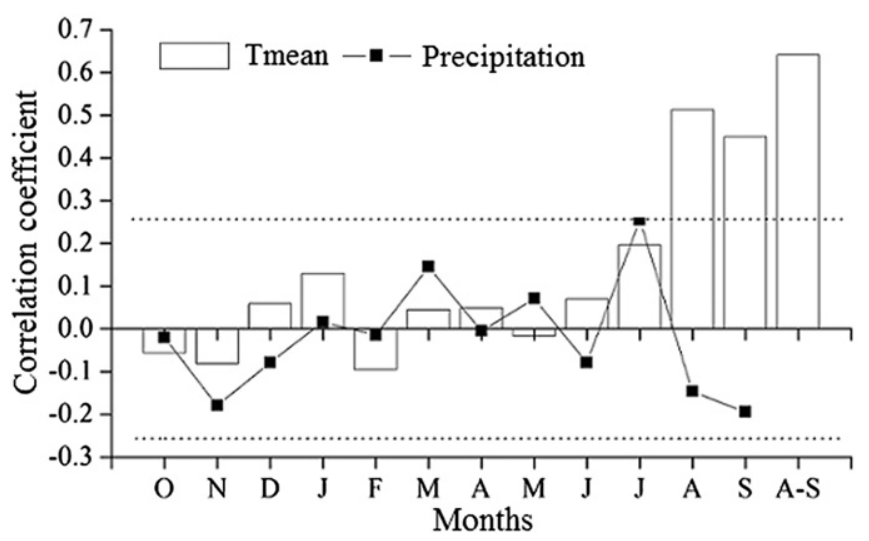

Fig. 4. Correlation coefficients between the regional MXD standard chronology and the gridded mean temperature (Tmean) and precipitation from the previous October to current September, as well as seasonal mean (August-September), during the period 1950-2008. The horizontal dotted lines indicate statistical significance of 0.05.
We extended mean August-September temperature data for our study area back to A.D. 1690 using this regression model, which placed emphasis on the inter-annual to multi-decadal scale variations. According to the reconstructed temperature time series (Fig. 6), the mean is $13.387^{\circ} \mathrm{C}$ and the standard deviation (SD) is 0.301 . Extremely warm summer temperatures occurred in $1703,1716,1724,1747,1770$, 1804, 1827, 1834, 1847, 1865, 1887, 1929, 1945, 1985, 1994, 2003 and 2007; singularities for low temperature summers were 1694, 1701, 1709, 1720, 1729, 1750, 1759, 1787, 1809, 1816, 1817, 1841, 1857, $1885,1905,1913,1937,1951,1962$ and 1987 . On the decadal timescale, the smoothed (11-year low-pass filter) curve of the reconstructed temperature series displays obviously warm periods during $1734-1745$, the 1770 s, $1824-1840$, the 1890s, 1927-1936, the 1940s-1950s and 20022008. Cold episodes appeared during 1695-1702, 1806-1821, the 1850 s, 1882-1889, the 1900s and the 1960s. MTM spectral analysis of the temperature reconstruction displayed highly significantly $(P<0.01)$ spectral peaks at 2.2, 3.5 and 12.2 years (Fig. 7). Significant $(P<0.05)$ cyclic patterns were also found at 2.0, 2.1, 2.3, 2.7, 11.0, 27.5 and 59.8 years.

Spatial correlations of our reconstruction with the gridded temperature dataset during the period 1950-2008 showed that the significant $(P<0.1)$ correlation fields covered a broad region approximately $23-$ $35^{\circ} \mathrm{N}, 83-105^{\circ} \mathrm{E}$, located in the southeastern and southern TP, with the highest correlations $(R>0.6)$ appearing in the north-south oriented Hengduan Mountains and the eastern part of Himalayas $\left(27-32^{\circ} \mathrm{N}\right.$, $95-100^{\circ} \mathrm{E}$ ) (Fig. 8a). Additionally, the significant correlation fields emerged in southeast China, covering a much smaller area. To investigate the spatial correlations at high-frequency domain, we further correlated the first differences of the reconstruction with the gridded temperature dataset over the 1951-2008 period and even found larger significant $(P<0.1)$ correlation fields covering the region about 20 $36^{\circ} \mathrm{N}, 80-113^{\circ} \mathrm{E}$ (Fig. 8b) in comparison to the original data. The closest association fields $(R>0.6)$ for the first differences, however, only confined to a much smaller region about $27-32^{\circ} \mathrm{N}, 94-99^{\circ} \mathrm{E}$ (the Hengduan Mountains and the eastern part of Himalayas), which was very similar to those of the original data. Overall, the spatial correlation results confirm that our reconstruction captures broad-scale regional temperature variations in the southeastern and southern TP, especially in the Hengduan Mountains and the eastern part of Himalayas. Moreover, the reconstruction tracks temperature variability in some areas of south-east China to some degree.

\section{Discussion}

\subsection{The relationship of MXD and climate}

A number of previous studies involving the responses of maximum tree-ring density to climate at northern high latitudes and high altitudes have demonstrated the significant positive relationships between MXD and summer temperatures (Parker and Henoch, 1971; Briffa et al., 1990; Schweingruber et al., 1991; Wang et al., 2010; Jones et al., 2013). In the present study, we found a high positive correlation of the MXD standard chronology with August-September temperature, suggesting that L. speciosa forests growing at the upper tree-line of the Gaoligong Mountains, southeastern TP were likely to be influenced by late summer temperature. Temperature conditions in late summer during the 
Table 3

Statistics of calibration and leave-one-out verification results over the common period 1950-2008.

\begin{tabular}{|c|c|c|c|c|c|c|c|c|}
\hline & \multicolumn{4}{|c|}{ Calibration (original model: $\mathrm{Y}=7.355 \mathrm{X}+6.058$ ) } & \multicolumn{4}{|c|}{ Leave-one-out verification } \\
\hline & $R$ & $R^{2}$ & $R_{\text {adj }}^{2}$ & $F$ & $r$ & ST & Pmt & $\mathrm{RE}$ \\
\hline Original (1950-2008) & 0.640 & 0.409 & 0.399 & 39.503 & 0.605 & $41+/ 18-$ & 3.911 & 0.364 \\
\hline First difference (1951-2008) & 0.608 & 0.369 & 0.358 & 32.757 & 0.499 & $47+/ 11-$ & 2.572 & 0.254 \\
\hline
\end{tabular}

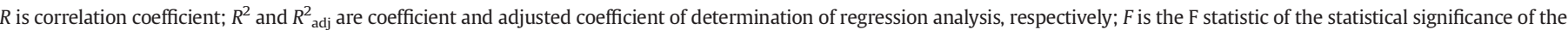

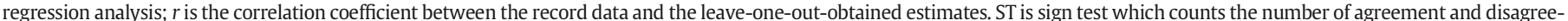

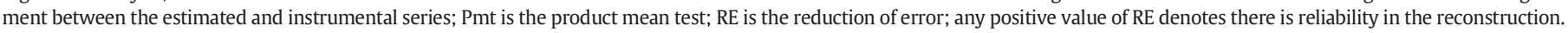

current growing season affect the number and wall thickness of latewood cells which determine the variations in MXD (Yasue et al., 2000; Hughes, 2001). Therefore, warmer temperature in the late summer can contribute in producing denser latewood. Our study confirms that there is a close relationship between the MXD of $L$. speciosa and late summer temperature, implying that the MXD of this species might have a great potential for temperature reconstruction and can even be used as an indicator of changes in climate.

\subsection{Validation for our summer temperature reconstruction}

\subsubsection{Tree-ring inferred temperature variations in surrounding regions}

Tree-ring studies regarding temperature reconstruction in surrounding regions can provide a reference for validating our reconstruction. The decadal variations (11-year low-pass filter) in August-September temperature reconstructed in the present study agrees with those for many other temperature time series inferred from tree-ring density in the southeastern, southern and eastern TP (Fig. 9). Cold periods during the 1810s, 1900s-1920s and 1960s presented in Changdu, eastern Tibet (Wang et al., 2010) and central Hengduan Mountains, southern China (Fan et al., 2009) were also indicated by the MXD of $L$. speciosa in our study area. Also, the conspicuously cold interval for the 1850s in our reconstruction was also shown in the MXD inferred August-September temperature time series in Linzhi (Bräuning and Mantwill, 2004) and Changdu (Wang et al., 2010), eastern TP. Warm phases in the 1820s, 1890s and 1930s-50s found in our study area were consistent with relatively high temperatures in Linzhi, eastern TP (Bräuning and Mantwill, 2004), the central Hengduan Mountains, southern China (Fan et al.,
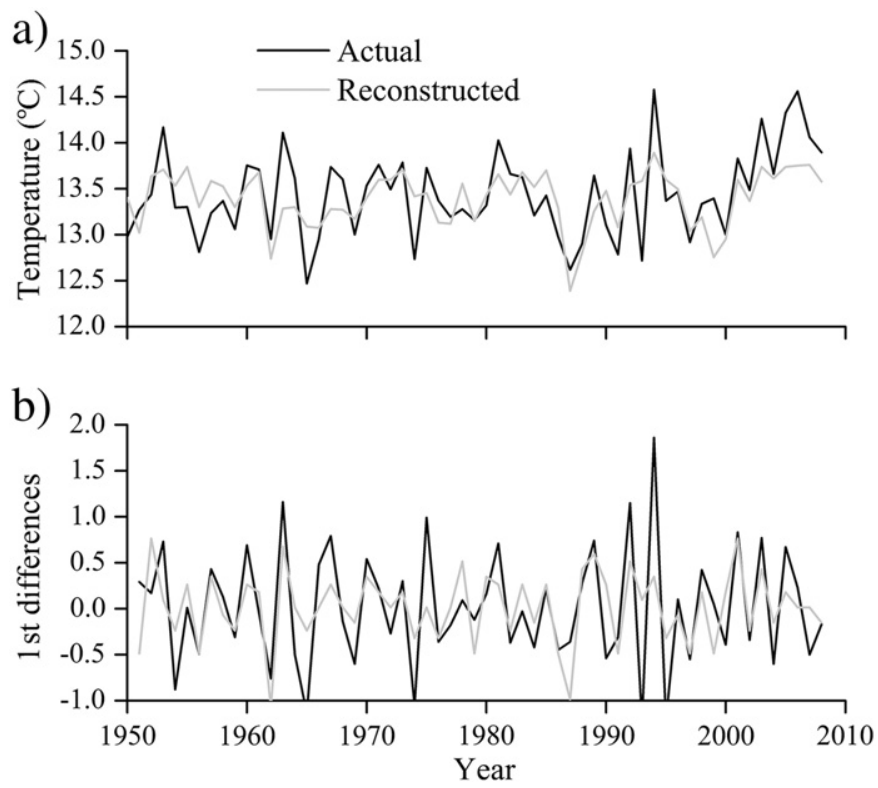

Fig. 5. (a) Comparison of the actual (black line) and reconstructed (grey line) mean August-September temperature for their common period 1950-2008. (b) Comparison of the 1st differences of actual (black line) and reconstructed (grey line) mean AugustSeptember temperature during the period 1950-2008.
2009) and Changdu, eastern TP (Wang et al., 2010). The warm periods in the 1930s-1950s were also exhibited in the reconstructed summer temperature series for the source region of Yangtze River (Liang et al., 2008). Although there are less similarities for these reconstructed temperature series before A.D. 1800, the cold period 1695-1705 and the warm period in the 1770s in our reconstruction were respectively consistent with the relatively low and high temperatures showed in the reconstructed August-September temperature series for Linzhi (Bräuning and Mantwill, 2004) and Changdu (Wang et al., 2010), eastern Tibet.

\subsubsection{Glacier fluctuations}

Advance and retreat of glacier is largely determined by changes in temperature, especially by summer temperature (Lowell, 2000; Liang et al., 2008). Therefore, we can use the historical glacier fluctuations in surrounding region to validate our reconstruction. The cold periods in the 1900s and 1960s corresponded to glacier advance in the Gongga Mountains of the eastern Tibetan Plateau (Li and Su, 1996) and in the Jade Dragon Snow Mountain of northwest Yunnan (He et al., 2003). Also, the cold episode during the 1960s was consistent with the accumulation period of Hailuogou glaciers in the southeastern TP (Li et al., 2010; Duan et al., 2013). The warm phases during the 1940s-1950s, however, coincide with the rapid retreats of the glacier in the Gongga Mountains (Li and Su, 1996; Li et al., 2010; Duan et al., 2013) and the Meili Snow Mountain (Zheng et al., 1999). Conspicuous period with high temperature during the 1770s in our reconstruction was approximately concurrent with the beginning of retreat for Midui (Xu et al., 2012) and Xinluhai (Bräuning, 2006) glacier in the southeastern TP, occurred in 1767 and 1777, respectively. Thus, the reconstructed AugustSeptember temperature variability in this study may be used as an indicator of past glacier fluctuations in nearby areas to some extent.

\subsubsection{Historical climatic records}

Few climatic records within and around our study region are available before the 1950s, although historical records might be a useful information to validate our reconstruction. Documental records in Lhasa displayed a cold period in the early 1900s and a warm phase during most of the 1940s-50s (Liu and Chen, 2000) which were consistent with the corresponding cold and warm intervals in our reconstruction. The years 1816 and 1817 as two obviously cold years in our reconstructed temperature series were also recorded in some historical documents for Yunnan province (Yang et al., 2005; Liu et al., 2006). The extremely low temperature in these two years, with the August temperatures

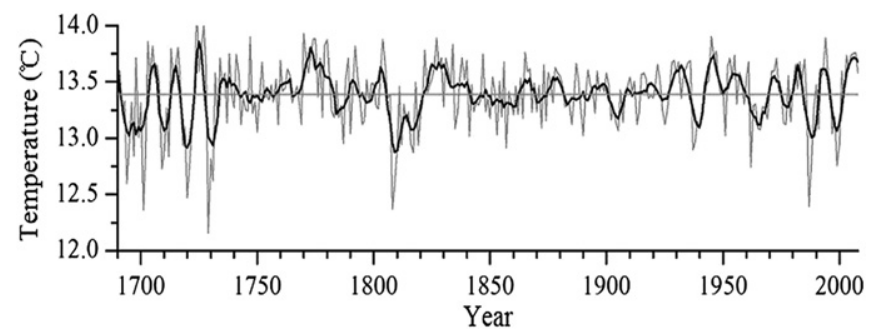

Fig. 6. Reconstructed mean August-September temperature (grey line) since A.D. 1690 from MXD with 11-year low-pass filter (thick black line). 


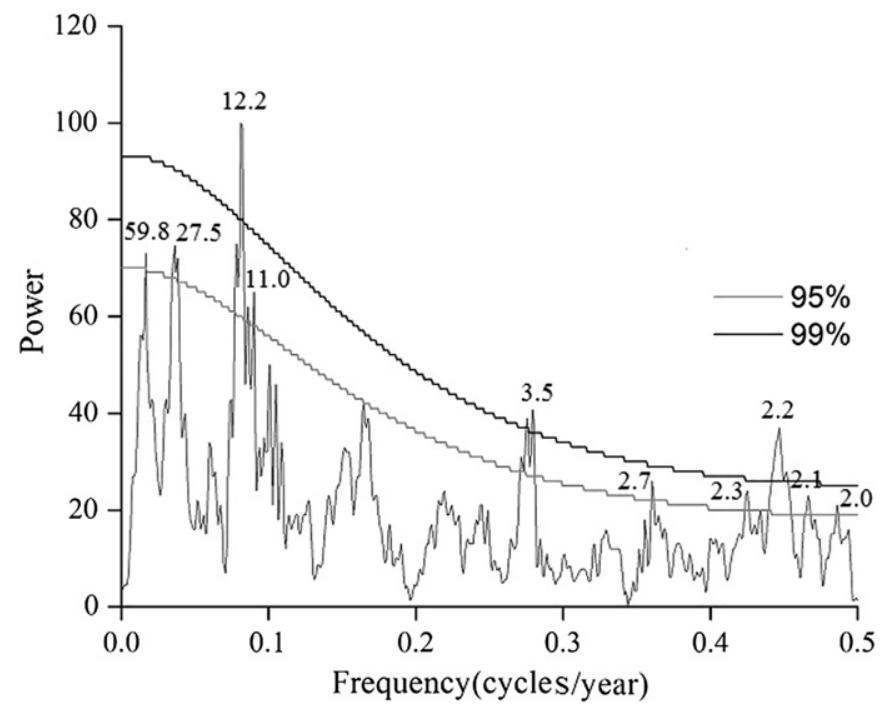

Fig. 7. Multiple-taper method (MTM) spectral analysis of the reconstructed mean AugustSeptember temperature. The grey and black lines indicate $95 \%$ and $99 \%$ confidence limits, respectively.

being about $2.5-3{ }^{\circ} \mathrm{C}$ lower than those for other normal years, led to a serious famine that occurred in most areas of the province (Yang et al., 2005). In addition to Yunnan, the cold years in 1816 and 1817 were also widely reported in other areas of the world, especially for Europe and North America (Filion et al., 1986; Briffa et al., 1998), which were considered to be related to the known Tambora (Indonesia) eruption that occurred in 1815 (Sigurdsson and Carey, 1992).

\subsection{Possible driving forces for the temperature variability in the Gaoligong} Mountains, southeastern TP

The results of the MTM spectral analysis indicated the existence of several important cycles in our reconstruction, which may be used to explain the temperature variations in the study region. The $2-4$ year cycles fall within the spectral bandwidth (2-8 years) of El Nino Southern Oscillation (ENSO) (Bradley et al., 1987). In accordance with this observation, several previous studies also indicated a possible linkage between ENSO and temperature variability of the Tibetan Plateau (Yin et al., 2000; Liang et al., 2008; Zhang et al., 2014). It has been proved that ENSO can modulate effectively temperature variability in the tropics and even across the globe (Trenberth et al., 2002; Gu and Adler, 2010), with warming up following an El Nino event (Newell

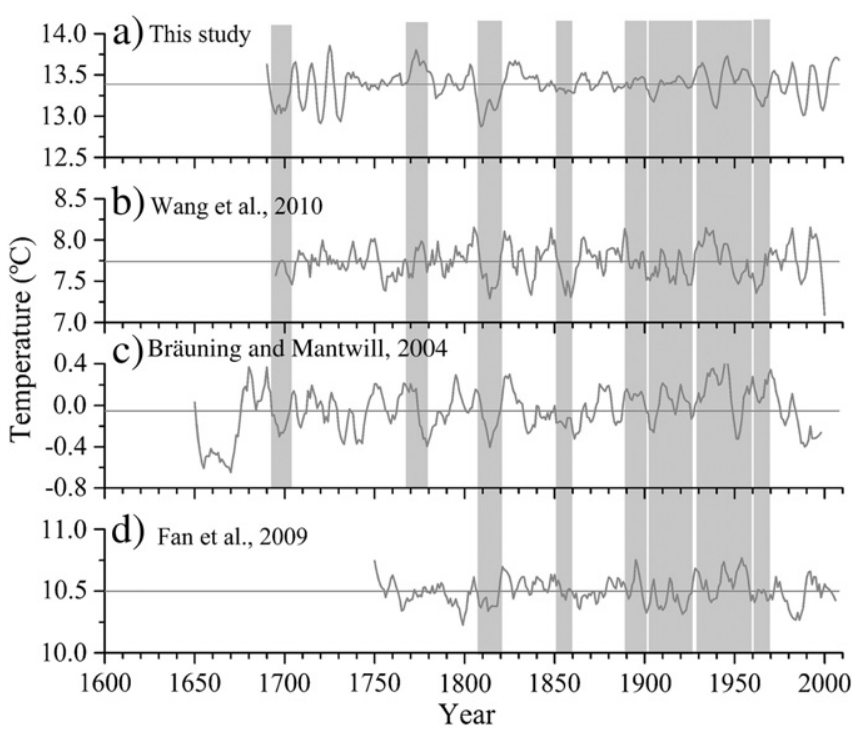

Fig. 9. Comparison of the reconstructed mean August-September temperature series in this study with other tree-ring density inferred temperature series. (a) Mean AugustSeptember temperature reconstruction for the Gaoligong Mountains, southeastern Tibetan Plateau from our study; (b) Mean August-September temperature reconstructed from maximum tree-ring density (MXD) in Changdu, eastern Tibet (Wang et al., 2010): (c) Mean August-September temperature reconstructed from MXD in Linzhi, eastern Tibet (Bräuning and Mantwill, 2004); (d) Mean April-September temperature reconstructed from MXD in the central Hengduan Mountains in southern China (Fan et al. 2009). The thick curves denote the 11-year low-pass filtered values and the horizontal lines indicate the long-term means.

and Weare, 1976). Warm ENSO event corresponded to the weakening of Indian monsoon (Kumar et al., 1999) which could decrease precipitation and hence reduce its cooling effect, resulting in above-normal temperature in our study area, a shoulder region of the Indian monsoon. The spectral peaks of 11.0 and 12.2 years were approximately equivalent to the cycle of solar activity which can affect the temperature variations on the earth as well as the TP. Tree-ring data from Sygera Mountain (Wang and Zhang, 2011) and Zuogong (Duan and Zhang, 2014), southeastern TP also displayed a cycle of about 11 years, indicating a possible effect of solar activity on tree growth through influencing temperature variations. The multi-decadal variability at spectral peaks of 27.5 and 59.8 years may correspond to the Pacific Decadal Oscillation (PDO) (Mantua et al., 1997). As shown in Fig. 10, the August-September temperature series reconstructed in this study agrees with the instrumental (Mantua et al., 1997) and reconstructed (MacDonald and Case, 2005) PDO variations during the period in the 1940s-1990s. Moreover, similar

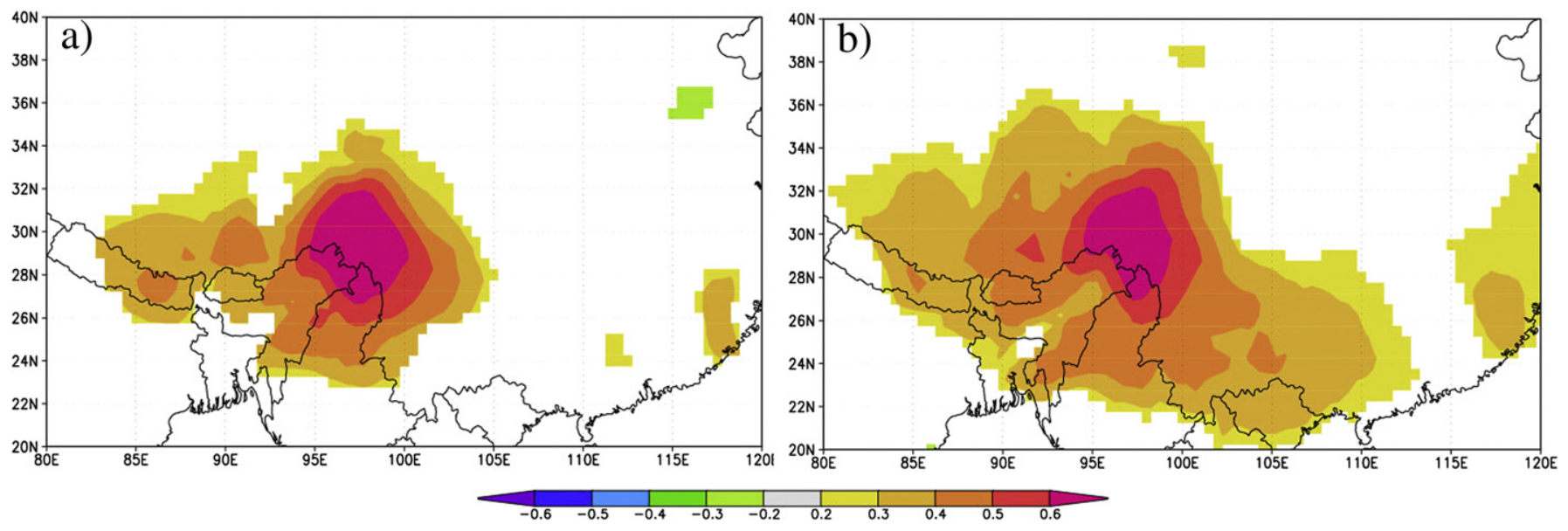

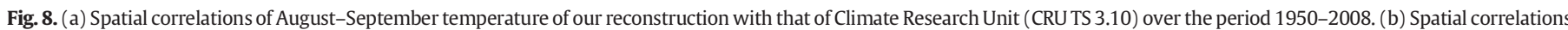
of the 1st differences of August-September temperature of our reconstruction with that of Climate Research Unit (CRU TS 3.10) during the 1950-2008 period. 


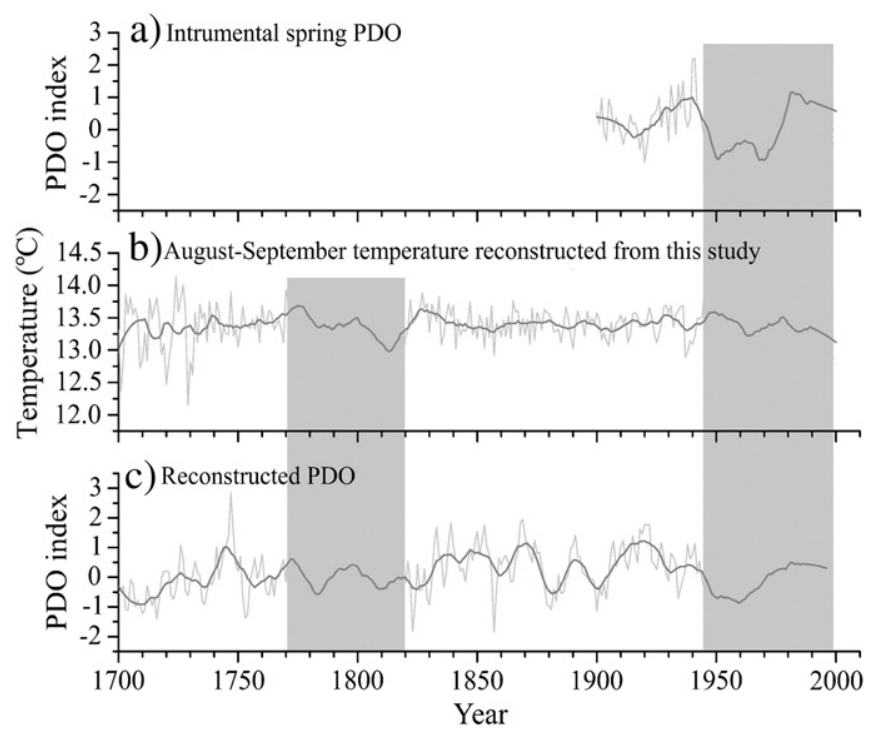

Fig. 10. Graphical comparison of August-September temperature reconstructed in this study (b) with two PDO indexes: (a) Instrumental spring (March-April-May) PDO index during the period 1900-2000 (Mantua et al., 1997) and (c) reconstructed PDO index from MacDonald and Case (2005).

fluctuation pattern was displayed between the reconstructed temperature series and PDO index over the period in the 1770s-1810s. Therefore, PDO might be a driving force for the temperature variations in our study region. Tree-ring based temperature constructions in surrounding areas, such as the Changdu, southeastern TP (Wang et al., 2010), the source region of Yangtze River, eastern TP (Liang et al., 2008) and the Qilian Mountains, northeastern TP (Zhang et al., 2014) also suggested a possible relationship between the temperature variability and PDO. Besides the above factors, the volcanic explosion was probably an important driving force for temperature anomalies in our study area. Fine ash and gas developed in volcanic explosion can spread widely and consequently hinder the entry of sunshine to the Earth's surface, leading to the occurrence of low temperature (de Silva and Zielinski, 1998). The cold years 1809, 1810 and 1816 in our reconstruction corresponded separately to the volcanic eruption in 1808 (Chenoweth, 2001), 1809 (Dai et al., 1991) and 1815 (Sigurdsson and Carey, 1992), since a cold weather generally follows a volcanic event occurred in the previous year (Briffa et al., 1998).

\section{Conclusions}

1) The maximum tree-ring density (MXD) of $L$. speciosa growing near the upper tree line of the Gaoligong Mountains, southeastern TP is sensitive to temperature variations in late summer. The developed MXD standard chronology of this species can well explain the actual variance in the August-September temperature (40.9\%) as well as its first differences (36.9\%) during the calibration period 1950-2008. This study demonstrates the potential of using the tree-ring density of larch (L. speciosa) to infer temperature variability in the southeastern TP.

2) The reconstructed August-September temperature history for our study area based on the MXD index series, which highlights the inter-annual to multi-decadal scale variability, can capture broadscale regional temperature variability in the southeastern and southern TP. Comparison of the present reconstruction with other documents in nearby regions indicates consistent cold/warm episodes at the decadal scale, i.e. cold periods during the 1810 s, 1900s-1920s, 1960s and warm phases during the 1820s, 1890s and 1930s-50s. Our reconstruction provides a new temperature record for the southeastern TP, which, to some degree, improves the spatial coverage of available proxy records in this region.
3) The temperature variability in the Gaoligong Mountains, southeastern TP might have been related to ENSO, solar activity, PDO and volcanic explosion.

\section{Acknowledgements}

The authors extend many thanks to two anonymous reviewers for their valuable comments and suggestions on the revisions of the manuscript. We also thank Prof. Bräuning A. who kindly provided their data. Climate data for the Deqin station were obtained from the National Meteorological Information Centre of China. This work was financially supported by the National Natural Science Foundation of China (no. 41271120), the National Public Benefit (Meteorology) Research Foundation of China (GYHY201206014) and "135" Strategic Project of Institute of Geographic Sciences and Natural Resources Research, Chinese Academy of Sciences (2012ZD001).

\section{Supplementary data}

Supplementary data associated with this article can be found in the online version, at http://dx.doi.org/10.1016/j.palaeo.2015.01.003. These data include Google maps of the most important areas described in this article.

\section{References}

Biondi, F., Waikul, K., 2004. DENDROCLIM2002: AC++ program for statistical calibration of climate signals in tree-ring chronologies. Comput. Geosci. 30, 303-311.

Bradley, R.S., Diaz, H.F., Kiladis, G.N., Eischeid, J.K., 1987. ENSO signal in continental temperature and precipitation records. Nature 327, 497-501.

Bräuning, A., 2006. Tree-ring evidence of 'Little Ice Age' glacier advances in southern Tibet. The Holocene 16 (3), 369-380.

Bräuning, A., Mantwill, B., 2004. Summer temperature and summer monsoon history on the Tibetan plateau during the last 400 years recorded by tree rings. Geophys. Res. Lett. 31, L24205. http://dx.doi.org/10.1029/2004GL020793.

Briffa, K.R., Bartholin, T.S., Eckstein, D., Jones, P.D., Karlen, W., Schweingruber, F.H., Zetterberg, P., 1990. A 1400-year tree-ring record of summer temperatures in Fennoscandia. Nature 346, 434-439.

Briffa, K.R., Jones, P.D., Schweingruber, F.H., 1992. Tree-ring density reconstruction of summer temperature patterns across western North America since 1600. J. Clim. 5, 735-754.

Briffa, K.R., Jones, P.D., Schweingruber, F.H., Osborn, T.J., 1998. Influence of volcanic eruptions on Northern Hemisphere temperature over the past 600 years. Nature 393, 450-455.

Chenoweth, M., 2001. Two major volcanic cooling episodes derived from global marine air temperature, A.D. 1807-1827. Geophys. Res. Lett. 28, 2963-2966.

Cook, E.R., 1985. A time-series analysis approach to tree-ring standardization. Ph.D. Thesis. University of Arizona Press, Tucson.

Cook, E.R., Kairiukstis, L.A., 1990. Methods of dendrochronology. Kluwer Academic Press, Dordrecht, Netherlands.

Dai, J.H., Mosley-Thompson, E., Thompson, L.G., 1991. Ice core evidence for an explosive tropical volcanic eruption 6 years preceding Tambora. J. Geophys. Res. 96, 17361-17366.

de Silva, S.L., Zielinski, G.A., 1998. Global influence of the AD 1600 eruption of Huaynaputina, Peru. Nature 393, 455-457.

Duan, J., Zhang, Q.B., 2014. A 449 year warm season temperature reconstruction in the southeastern Tibetan Plateau and its relation to solar activity. J. Geophys. Res. Atmos. 119 (1157), 8-11592.

Duan, J.P., Wang, L.L., Li, L., Sun, Y., 2013. Tree-ring-inferred glacier mass balance variation in southeastern Tibetan Plateau and its linkage with climate variability. Clim. Past 9, 2451-2458.

Fan, Z.X., Bräuning, A., Cao, K.F., 2008. Tree-ring based drought reconstruction in the central Hengduan Mountains (China) since A.D. 1655. Int. J. Climatol. 28, 1879-1887.

Fan, Z.X., Bräuning, A., Yang, B., Cao, K.F., 2009. Tree ring density-based summer temperature reconstruction for the central Hengduan Mountains in southern China. Glob. Planet. Chang. 65, 1-11.

Fan, Z.X., Bräuning, A., Tian, Q.H., Yang, B., Cao, K.F., 2010. Tree ring recorded May-August temperature variations since A.D. 1585 in the Gaoligong Mountains, southeastern Tibetan Plateau. Palaeogeogr. Palaeoclimatol. Palaeoecol. 296, 94-102.

Filion, L., Payette, S., Gauthier, L., Boutin, Y., 1986. Light rings in subarctic conifers as a dendrochronological tool. Quat. Res. 26 (2), 272-279.

Fritts, H.C., 1976. Tree-Rings and Climate. Academic Press, London.

Gou, X.H., Chen, F.H., Jacoby, G., Cook, E.R., Yang, M.X., Peng, J.F., Zhang, Y., 2007. Rapid tree growth with respect to the last 400 years in response to climate warming, northeastern Tibetan Plateau. Int. J. Climatol. 27, 1497-1503.

Gou, X.H., Peng, J.F., Chen, F.H., Yang, M., Levia, D.F., Li, J., 2008. A dendrochronological analysis of maximum summer half-year temperature variations over the past 
700 years on the northeastern Tibetan Plateau. Theor. Appl. Climatol. 93 (3-4), 195-206.

Gu, G.J., Adler, R.F., 2010. Precipitation and temperature variations on the interannual time scale: assessing the impact of ENSO and volcanic eruptions. J. Clim. 24, $2258-2270$.

Harris, I., Jones, P.D., Osborn, T.J., Lister, H., 2013. Updated high-resolution grids of monthly climatic observations. Int. J. Climatol. 34 (3), 623-642.

He, Y.Q., Zhang, Z., Yao, T.D., Chen, T., Pang, H.X., Zhang, D., 2003. Modern changes of the climate and glaciers in China's monsoonal temperature glacier region. Acta Geograph. Sin. 58 (4), 550-558 (in Chinese).

Holmes, R.L., 1983. Computer-assisted quality control in tree-ring dating and measurement. Tree-Ring Bull. 43, 69-78.

Hughes, M.K., 2001. An improved reconstruction of summer temperature at Srinagar, Kashmir since 1660 AD based on tree-ring width and maximum latewood density of Abies pindrow [Royle] Spach. Palaeobotanist 50, 13-19.

Jones, P.D., Melvin, T.M., Harpham, C., Grudd, H., Helama, S., 2013. Cool North European summers and possible links to explosive volcanic eruptions. J. Geophys. Res. 118, 6259-6265.

Kumar, K.K., Rajagopalan, B., Cane, M.A., 1999. On the weakening relationship between the Indian monsoon and ENSO. Science 284, 2156-2159.

Lenz, O., Schaer, E., Schweingruber, F.H., 1976. Methodische Probleme bei der radiographisch- densitometrischen Bestimmung der Dichte und der Jahrringbreiten von Holz. Holzforschung 30 (4), 114-123.

Li, J.J., Su, Z., 1996. Glaciers in the Hengduan Mountains. Science Press, Bejing (in Chinese).

Li, H., Guo, H.J., Dao, Z.L., 2000. Flora of Gaoligong Mountains. Science Press, Beijing (in Chinese).

Li, Z.X., He, Y.Q., Pu, T., Jia, W.X., He, X.Z., Pang, H.X., Zhang, N.N., Liu, Q., Wang, S.J., Zhu, G.F., Wang, S.X., Chang, L., Du, J.K., Xin, H.J., 2010. Changes of climate, glaciers and runoff in China's monsoonal temperate glacier region during the last several decades. Quatern. Int. 218, 13-28.

Li, Z.S., Zhang, Q.B., Ma, K., 2012. Tree-ring reconstruction of summer temperature for A.D. 1475-2003 in the central Hengduan Mountains, Northwestern Yunnan, China. Clim. Chang. 110, 455-467.

Liang, E.Y., Shao, X.M., Qin, N.S., 2008. Tree-ring based summer temperature reconstruction for the source region of the Yangtze River on the Tibetan Plateau. Glob. Planet. Chang. 61, 313-320.

Liang, E.Y., Shao, X.M., Xu, Y., 2009. Tree-ring evidence of recent abnormal warming on the southeast Tibetan Plateau. Theor. Appl. Climatol. 98 (1-2), 9-18.

Liu, X.D., Chen, B.D., 2000. Climatic warming in the Tibetan Plateau during recent decades. Int. J. Climatol. 20, 1729-1742.

Liu, X.H., Qin, D.H., Shao, X.M., Chen, T., Ren, J.W., 2005. Temperature variations recovered from tree-rings in the middle Qilian Mountains over the last millennium. Sci. China Ser. D 48 (4), 521-529.

Liu, Y., An, Z.S., Ma, H.Z., Cai, Q.F., Liu, Z.Y., Kutzbach, J.K., Shi, J.F., Song, H.M., Sun, J.Y., Yi, L., Li, Q., Yang, Y.K., Wang, L.L., 2006. Precipitation variation in the northeastern Tibetan Plateau recorded by the tree rings since $850 \mathrm{AD}$ and its relevance to the Northern Hemisphere temperature. Sci. China Ser. D 49, 408-420.

Liu, Y., An, Z.S., Linderholm, H.W., Chen, D.L., Song, H.M., Cai, Q.F., Sun, J.Y., Tian, H., 2009. Annual temperatures during the last 2485 years in the mid-eastern Tibetan Plateau inferred from tree rings. Sci. China Ser. D 52 (3), 348-359.

Lowell, T.V., 2000. As climate changes, so do glaciers. PNAS 97, 1351-1354.

MacDonald, G.M., Case, R.A., 2005. Variations in the pacific decadal oscillation over the past millennium. Geophys. Res. Lett. 32, L08703. http://dx.doi.org/10.1029/ 2005 GL022478.

Manabe, S., Terpstra, T.B., 1974. The effects of mountains on the general circulation of the atmosphere as identified by numeral experiments. J. Atmos. Sci. 31 (1), 101-112.

Mann, M.E., Lees, J.M., 1996. Robust estimation of background noise and signal detection in climatic time series. Clim. Chang. 33, 409-445.

Mantua, N.J., Hare, S.R., Zhang, Y., Wallace, J.M., Francis, R.C., 1997. A Pacific interdecadal climate oscillation with impacts on salmon production. Bull. Am. Meteorol. Soc. 78, 1069-1079.

Michaelsen, J., 1987. Cross-validation in statistical climate forecast models. J. Clim. Appl. Meteorol. 26, 1589-1600.

Mitchell, T.D., Jones, P.D., 2005. An improved method of constructing a database of monthly climate observations and associated high-resolution grids. Int. J. Climatol. $25,693-712$.

Myers, N., Mittermeier, R.A., Mittermeier, C.G., Fonseca, G.A.B., Kent, J., 2000. Biodiversity hotspots for conservation priorities. Nature 403, 853-858.

Newell, R.E., Weare, B.C., 1976. Factors governing tropospheric mean temperatures. Science 194, 1413-1414.
Parker, M.L., Henoch, W.E.S., 1971. The use of Engelmann spruce latewood density for dendrochronological purposes. Can. J. For. Res. 1, 90-98.

Sano, M., Tshering, P., Komori, J., Fujita, K., Xu, C.X., Nakatsuka, T., 2013. May-September precipitation in the Bhutan Himalaya since 1743 as reconstructed from tree ring cellulose $\delta^{18} \mathrm{O}$. J. Geophys. Res. Atmos. 118, 8399-8410.

Schweingruber, F.H., 1988. Tree ring - basic and applications of dendrochronology. Paul Haupt Press, Berne.

Schweingruber, F.H., Briffa, K.R., Jones, P.D., 1991. Yearly maps of summer temperatures in Western Europe from A.D. 1750 to 1975 and Western North America from 1600 to 1982: results of a radiodensitometrical study on tree rings. Vegetatio 92, 5-71.

Shao, X.M., Huang, L., Liu, H.B., Liang, E.Y., Feng, X.Q., Wang, L.L., 2005. Reconstruction of precipitation variation from tree rings in recent 1000 years in Delingha, Qinghai. Sci. China Ser. D 48 (7), 939-949.

Sigurdsson, H.S., Carey, S., 1992. The eruption of Tambora in 1815: environmental effects and eruption dynamics. In: Harington, C.R. (Ed.), The Year Without a Summer? World Climate in 1816. Canadian Museum of Nature, Ottawa, pp. 16-45.

Trenberth, K.E., Caron, J.M., Stepaniak, D.P., Worley, S., 2002. Evolution of El NinoSouthern Oscillation and global atmospheric surface temperatures. J. Geophys. Res. 107, 40-65.

Wang, Z., Zhang, S.Y., 1992. China larch forest. Chinese Forestry Publishing House, Beijing (in Chinese).

Wang, X.C., Zhang, Q.B., 2011. Evidence of solar signals in tree rings of Smith fir from Sygera Mountain in southeast Tibet. J. Atmos. Sol. Terr. Phys. 73, 1959-1966.

Wang, Z.H., Tang, Z.Y., Fang, J.Y., 2007. Altitudinal patterns of seed plant richness in the Gaoligong Mountains, south-east Tibet, China. Divers. Distrib. 13, 845-854 (in Chinese).

Wang, L.L., Duan, J.P., Chen, J., Huang, L., Shao, X.M., 2010. Temperature reconstruction from tree-ring maximum density of Balfour spruce in eastern Tibet, China. Int J. Climatol. 30, 972-979.

Wigley, T., Briffa, K.R., Jones, P.D., 1984. On the average value of correlated time series, with applications in dendroclimatology and hydrometeorology. J. Clim. Appl Meteorol. 23, 201-213.

Xu, G.B., Chen, T., Liu, X.H., Jin, L.Y., An, W.L., Wang, W.Z., 2011. Summer temperature variations recorded in tree-ring delta C-13 values on the northeastern Tibetan Plateau. Theor. Appl. Climatol. 105 (1-2), 51-63.

Xu, P., Zhu, H.F., Shao, X.M., Yin, Z.Y., 2012. Tree ring-dated fluctuation history of Midui glacier since the little ice age in the southeastern Tibetan plateau. Sci. China Earth Sci. 55, 521-529.

Xue, J.R., 1995. Gaoligong Mountain National Nature Reserve. Chinese Forestry Publishing House, Beijing (in Chinese).

Yadav, R.R., Misra, K.G., Kotlia, B.S., Upreti, N., 2014. Premonsoon precipitation variability in Kumaon Himalaya, India over a perspective of similar to 300 years. Quatern. Int 325, 213-219.

Yang, Y.D., Man, Z.M., Zheng, J.Y., 2005. A serious famine in Yunnan (1815-1817) and the eruption of Tambora Volcano. Fudan J. 1, 79-85 (in Chinese).

Yasue, K., Funada, R., Kobayashi, O., Ohtani, J., 2000. The effects of tracheid dimensions on variations in maximum density of Picea glehnii and relationships to climatic factors. Trees 14, 223-229.

Yin, Z.Y., Lin, Z.Y., Zhao, X.Y., 2000. Temperature anomalies in central and eastern Tibetan Plateau in relation to general circulation patterns during 1951-1993. Int. J. Climatol. 20, 1431-1449.

Zhang, Z.H., Wu, X.D., 1997. Climatic reconstruction in the Qilian Mountains during the past 700 years using tree-ring data. Chin. Sci. Bull. 42, 849-851.

Zhang, Q.B., Cheng, G.D., Yao, T.D., Kang, X.C., Huang, J.G., 2003. A 2326-year tree-ring record of climate variability on the northeastern Qinghai-Tibetan Plateau. Geophys. Res. Lett. 30, L141739. http://dx.doi.org/10.1029/2003GL017425.

Zhang, Y., Shao, X.M., Yin, Z.Y., Tian, Q.H., 2013. A dendroclimatic analysis of regional moisture variation in the northeastern Tibetan Plateau during the past 150 years. Trees 27 (2), 455-463.

Zhang, Y., Shao, X.M., Yin, Z.Y., Wang, Y., 2014. Millennial minimum temperature variations in the Qilian Mountains, China: evidence from tree rings. Clim. Past 10, 1763-1778.

Zheng, B.X., Zhao, X.T., Li, T.S., Wang, C.Y., 1999. Features and fluctuation of the Melang glacier in the Mainri Mountain. J. Glaciol. Geocryol. 21 (2), 145-150 (in Chinese).

Zhu, H.F., Shao, X.M., Yin, Z.Y., Xu, P., Xu, Y., Tian, H., 2011. August temperature variability in the southeastern Tibetan Plateau since AD 1385 inferred from tree rings. Palaeogeogr. Palaeoclimatol. Palaeoecol. 305, 84-92. 